\title{
The Problems and the Countermeasures of the Service Manufacturing that Wuhan Develops
}

\author{
Yihong $\mathrm{Xu}^{1, \mathrm{a}^{*}}$, Ting $\mathrm{Liu}^{2, \mathrm{~b}}$ \\ ${ }^{1}$ Res earch Center of the Development of Manufacture in Wuhan City Circle, Jianghan University, \\ Hubei, 430056 \\ ${ }^{2}$ Res earch Center of the Development of Manufacture in Wuhan City Circle, Jianghan University, \\ Hubei, 430056 \\ a ${ }^{*}$ xuyihong_wh@hotmail.com, ${ }^{b} 1176145448 @ q q . c o m$
}

Keywords: Wuhan; Service; Manufacturing; Pattern; Mid-scale View

\begin{abstract}
Service manufacturing refers to the new pattern that highly combines with services manufacturing in the contest of economic globalization and rapid development in information technology. The purpose of the research and the countermeasures of the service manufacturing that Wuhan develops are to help China manufacturing convert its structure into a service as the model of service manufacturing to national manufacturing. This thesis uses methods of literature research, comparative study, case study, based on literature study it analyzes the problems faced by Wuhan when developing services manufacturing. That contains 5 aspects, for example it should enhance the consciousness of value chain extension and capacity, put forward for aspects of development countermeasure about "service manufacturing", pay attention to business process design and optimization. The thesis holds the opinion that service manufacturing will lead the global manufacturing in the 21st century, because it is a new idea and pattern. Developing service manufacturing in Wuhan can play an inestimable role in changing the way of economic growth, adjusting the industrial structure exceeding the value chain of enterprises and improving innovative concept of the enterprises. The most important is that it can drive and serve as a model to the transformation and development of the manufacturing.
\end{abstract}

\section{Introduction}

Service manufacturing refers to the new pattern that highly combines with services manufacturing in the contest of economic globalization and rapid development in information technology. After experiencing the 4 phases: rapid development of producer manufacturing, the reforms of consumer culture, intensifying competition and technical progress, service manufacturing make great reforms of manufacturing worldwide. The boundaries between manufacturing and service blur day by day, the percentage of service in the production value and theory in manufacturing enterprises gets higher and higher. In 1988, the percentage of four high income countries' service output in the whole economic is 68. The rapid development of service manufacturing has increasingly become many countries' main sources of the growth of economy.

China has been regarded as "manufacturing power" for a long time, however the China's manufacturing is still at the bottom of value chain, and China lakes the competitiveness and the international influences. That bound to impede the development of China's manufacturing. How to transform China's manufacturing successfully and how to get and maintains enterprises' long-term competitiveness is the big question that researchers have been exploded. Carrying out service manufacturing can help China's manufacturing to improve their structure. Service manufacturing is the great opportunity for China to transform from "foundary in China" to "made in ChinaChina", it will be mighty power for China's manufacturing to catch up with and surpass western developed 
countries. In the mean while, that is the significant guarantee to solve the country's problem of employment and main tain social stability.

Wuhan manufacturing has formed certain industry scale, it has plenty of manufacturing in different fields like steel, automobile and machinery, optoelectronics information, biological medicine, environmental protection food and tobacco, paper making and package printing, petrochemical engineering, household appliances and spinning and dress, what's more, the labor cost is lower compared to coastal cities, it has lots of technical talents, IT industries develop quickly, it has superior environment for the service oriented manufacturing, it's the core of the development in Hubei economies and the significant strategic location. The purpose of the research of the problems and the countermeasures of service manufacturing that Wuhan develops can provide new opportunity to the manufacturing of midland, and it can also serve as the model of service manufacturing to national manufacturing.

\section{The review of literature}

Service manufacturing. Service manufacturing also known as servitization of manufacturing refers to the new pattern that highly combines service with manufacturing. "Service manufacturing is the mew patter of advanced manufacturing in the world" (Zhao Xiaolei).Its purpose is to mount the value of those stakeholders who are in the same value of manufacturing. By the means of combing products with service, involving customers in the whole process, enterprises make use of Producer Service and production of services mutually. Then researchers can combine the scattered manufacturing resources; coordinate core competitiveness of each enterprise. Then attain the highly innovative new manufacturing mode.

Many countries have done research about service manufacturing: Australia name the service manufacturing as service-based manufacturing, America esteem the service manufacturing as service-based manufacturing, Britain name service manufacturing as Productive Service System, japan regard service manufacturing as Service Oriented Manufacturing. It is based on manufacture service and the manufacturing that aim at service, it's also based on the combination of product economy and consumptive service economy.it can be divided into three parts: macroscopic (the nationwide aspect), mid-scale view (industry and area), microcosmic (the aspect of enterprises).

As for the requirement for the new pattern of service manufacturing, the connotation of the enterprises' product has converted, and it requires to meet customers' demands with the form of "product-service systems". What is more, the delivery, design, and production of "product-service sy stems" will change with the change of the word under the circumstance of the network. These new changes will make the sustainability and the resources of value of service manufacturing better than traditional manufacturing. Now customers can participate in the production of products and the environments of network make the features of service manufacturing more special and specific.

The pattern and mechanism of value of service manufacturing. Sun Yanlin, Gao Jie etc have established and analyzed the product model of service manufacturing and BIT model. Cui Jiachen, Lin Wei etc have analyzed the delivery system of custom value with the pattern service manufacturing, how the participation of customers will influence the delivery system of customer value chain of manufacturing enterprises; construct theoretical models of relationships between the participation of customers and the service capacity of enterprises, between the customer perceived value and customers satisfaction degree. Lin Jianzong build the informational frame of service manufacturing and point out that the service manufacturing informatization needs to base on Process Re-engineering and Service Standard. He said that enterprises needed to combine with the informational resources within enterprise and among enterprises, dug out clients' in formation, and then shared them. He also said researchers should build a con generous platform involving the service and sale of products, purchase and collaborative manufacturing, comprehensive 
information management, scheduling and rescheduling, the management and design of products enterprise information gateway.

The reason of manufacturing industry service. China scholar Zhou Dapeng has elaborated the phenomenon of manufacturing industry servicizing from four aspects: knowledge-based economy, the extension of value chain, during force of income and environmental protection. His studies have careful analyzed the central part and the dominant right of value chain' added of manufacturing industry servicizing, the way, impetus and pressure of value chain' added. he thinks that researchers have to innovate knowledge in order to extend value chain, researchers have to accumulate knowled ge especially recessive knowledge before innovating knowledge, if researchers want to accumulate recessive knowledge you need the help of service manufacturing. All manuscripts, the tables and figure texts must be in English, otherwise researchers cannot publish your paper.

\section{The theoretical basis of service manufacturing}

The theoretical basis of service manufacturing has two aspects: the combination of theories in behavioral science traditional manufacturing, the combination of social network, the theory of responsible system and theory of organization.

Firstly service manufacturing try to integrate human's behaviors and sense to "product-service systems". In the process of manufacturing and delivery, the suppliers create and gain value together (the behavior of customer interaction).so if service manufacturing wants to achieve its value, it must have the participation and experience of clients.

Second, in the pattern of Service Manufacturing, the former contracting manufacturers, original facility manufacturers, producer service enterprises and manufacturing service enterprises will break the former situation to make up a website org anization spontan eou sly .Ev ery enterprise will provide the manufacturing towards services and the services towards manufacturing for each other. In addition, customers will participate in "the product service system."

\section{The issues Wuhan facing in developing Service Manufacturing}

The contradictions in manufacturing's innovative development. The contradictions between abundant science and technology and low level of industrialization. The contrast of the low level of high technology industrialization in Wuhan is outstanding, which is obvious in the commercialization and industrialization of technological achievements. On one hand, technology resources are owned by every department, every unit and every region so that it is difficult to share the research achievements and few opportunities can be provided for the technological talents to exchange experience and cooperate with each other.It result in the different innovation target, the weak innovative power and the small technological innovation unit with small scale and scattered funds, which cause the short of research funds. On the other hand,productive forces is not powerful enough to boost the organization functions, which is limited to improve the ability of transforming scientific research achievements.

The consciousness and capacity of extensive value chain awaiting improvement. Although Manufacturing in Wuhan have certain industry advantages and high technology ability, most enterprises in lack of the ability to turn product system into another system combined with products and services are still in the medium-end part of the value chain. It's urgent for them to further improve their innovative ability to realize the transform of the whole manufacturing. Those are department that Serves Manufacturing is indispensable. In order to realize the advantages of Manufacturing and improve the key competitiveness of enterprises, it's necessary to put customers' personal needs into products. 
The imperfect service system with problems itself. (1)The scale level of Service Industry in Wuhan is not high. In 2013, the increased value of all city's service industries ranked 10th among 19 cities deputy provincial level and above, which is lower than those cities by 102,899 billion Yuan. And it's also lower than Beijing (1066,680 billion Yuan), Shanghai (912,537 billion Yuan), Guangzhou (564,419billion Yuan), Shenzhen (387,844 billion Yuan), Tianjin (258,533 billion Yuan), Chongqing (93,639 billion Yuan), Chengdu (25,450 billion Yuan), Hang zhou (9,642 billion Yuan), Nanjing (3,686 billion Yuan); (2) Service Industry of areas of a city in Wuhan doesn't develop fast enough. Since the 12th Five-Year Plan, Wu han has been making great efforts to give impetus to develop industries, but the growth speed of service industry is always lower than the growth speed of the secondary industry at the same time, which is lagging comparatively. From 2011 to 2013,Service Industry respectively increased by $9.6 \%, 10.4 \%$ and $10.0 \%$, which is respectively lower than the secondary industry by 6.8 percentage points, 2.5 percentage points and 0.3 percentage points. In 2013, the GDP growth speed of Wuhan ranked 8th among 19 cities deputy provincial level and above, and the growth speed of its secondary industry ranked 7th, but the growth speed of service industry just ranked 10th.(3)The ratio of the service industry of areas of a city in Wuhan is falling year by year. From 2011 to 2013, the proportions of service industry in GDP respectively were $48.9 \%$, 47.9\% and $47.7 \%$, which tended to fall gradually. In the 19 cities deputy provincial level, there were 12 cities whose proportion of service industry in GDP IS more than $50 \%$. The proportion of the increased value of service industry of Wuhan ranked 14th. (4)There was little large scale service enterprise in Wuhan. In 2013, only 1477 service enterprises with certain scale, which was fewer than Chengdu by 116 and Hangzhou by 1146, and took the proportion of $27 \%$ in all legal service units. Only 224 en terprises' business scale are more than a hundred million, which take the proportion in enterprises with certain scale by $15.2 \%$.(5)The benefits of service industry in Wuhan is not high, which are affected by the rising cost of labors and business and the lack of market needs. In 2013, there were 302 loss-making enterprises which took the proportion of $20.5 \%$ in the service industries with certain scale. (6)Most manufacturing in Wuhan belong to traditional processing enterprises. The informationizing level of the operating about enterprises' resources is low, the constructive system of agent service is weak, the integration system and the enterprises' ability of management and consultancy service which are lack of the combination with design, manufacturing and service are inferior, and enterprises have not form a manufacturing system with specialized division and socialized infrastructure. This not only restricts the enterprises to become stronger, but also delay the process of Service Manufacturing.

The imperfect industry coordinated development mechanism and policy service system. The government's industrial plan, policy guide and official achievement examinations are still partial to manufacturing, which is still the leading of economic development. Service market monopoly and policy discrimination still exist and the global plan as a whole and regional industry development planning coordination mechanism are imperfect. All these lead to low level industry repeated investment and resource allocation, and reduce the intensive degree and competitiveness level of the industry. What's more, in the aspect of policy service systembuilding, there has been no real form relating perfect policy service system and market development mechanism to support the entire province manufacturing industry transformation of service, which will be the very important problems than Wuhan needs to solve in developing the Service Manufacturing.

\section{The Countermeasures to Promote the Service Manufacturing in Wuhan}

Establishing the theme of the multidimensional collaborative innovation strategy in Wuhan. Establish a service system of joint conference for the coordinated development of manufacturing industry and to form a trans-regional across industry chain innovation or organization in Wuhan. Establish a clear division of responsibilities and coordinate with strong and high efficiency work 
mechanism. Carry out a service manufacturing industry chain of innovation strategy and to optimize the innovation conditions and market environment. Based on the coordination and support of government, the enterprises cultivate the innovation ability as the core, market and social environment optimization for support. Through the government, industry, society, market multidimensional synergy, build technology industry chain and achieve effective docking of industry, science and technology. Have a key and step- by-step implementation. From regional economic synergy to core ability, from regional cluster core ability, thus forming a large number of industrial innovation main body with strong competitiveness.

The active cultivation andintroduction of a Service Manufacturing team of professional . The most urgent need of service economy and Service Manufacturing is the knowledge, professional and comprehensive talents. Service Manufacturing is the combination of human capital and knowledge capital conduction, and it is intensive knowledge components manufacturing. Only through the innovation, steadiness, and enterprising management team and with management thinking, market awareness of the technical team, the manufacturing enterprises could be able to realize the simple processing of low-end to technology design, two brand marketing shift. The enterprises should develop and introduce their research and development, information technology, the production operation and the quality control to supply the links and marketing talents, to build the learning organization, knowledge management team, and to build suitable survival and development platform for the knowledge workers and technical talents, and to make the talents that one of the most active part of the production factors in product upgrade play the greatest role in industrial transformation through fully releasing their energy.

Developing the Service Manufacturing and Improving the Efficiency of Resource Allocation. Everything seems to be at the stage of China's manufacturing enterprises in the expansion of some original thinking, the research of the enterprises, confession produce, sales integration of the traditional business model is still relatively common, independent research and development, design suppliers, overall solution provider and all kinds of professional intermediary service provider is not many. Low efficiency of resource allocation is the weakness of China's economic development, the manufacturing enterprises product backlog, low efficiency of founds, corporate profits and capital accumulation ability is very weak, innovative power and financial support dynamics is insufficient, the overall competitiveness is not strong. Developing and building the platform of Service Manufacturing (belonging to technology-intensive and knowledge-intensive service) and developing technology service and knowledge consulting and boosting the combination of service industry and manufacturing are helpful to adjust the economic construction, change the mean s of developing economy and improve the efficiency of resource allocation, which is a turning point to the development of China, a region, a city and an enterprise.

Attaching Importance to the Business Process Design and Optimization of the Service Manufacturing. The target of business process design is to employ the least resource needed in adding product service value to obtain the most value in product service and to meet customers' needs fully and to promote customers' satisfaction and business achievements. First, researchers should regard the customers' full satisfaction as the start point, basing on the competition strategy, and put customers' need element information towards product service, the advantage direction information of competition strategy, intensity need information and security ability need information into the whole business design. Make sure that every link cooperates with each other harmoniously. Second, persisting in the direction guide principles, give up the means which regard positions and department as an entity according to the traditional organization theory, and use the essential increasing business activities or events as the basic process design or reorganization integration, so as to form an organic business process with harmonious joint business activities, added value chain, and gradual safeguarding advantages. All manuscripts, the tables and figure texts must be in English, otherwise researchers cannot publish your paper. 


\section{Conclusions}

Service Manufacturing as a kind of broad-new concept and mode will become the 21th century global manufacturing. Whether to change the way of economic growth, or adjustment of industrial structure, both for the extension of enterprise value chain, or to the promotion of enterprise innovation idea for the protection of the en vironment, and energy saving of resources and so on all play an immeasurable role especially in the development of the manufacturing industry in the country, the effect is more obvious. The implantation of Service Manufacturing will help the country manufacturing industry structure upgrade. Service Manufacturing is a big opportunity for the country to turn from China foundry made to China creating, this will be the Chinese society of manufacturing a powerful level to catch up with the western developed countries, but also solve the employment problem in the country at present and an important guarantee of maintaining social stability.

The problems Wuhan is faced with in developing Service Manufacturing are the conflicts of innovative manufacturing development, the sense and ability of extensive value chain needed to improve, the issues existing in service industry itself and the imperfect of the service system, and the imperfect of the service system, and the imperfect of harmoniou s industry development mechanism and policy service system.

Wuhan manufacturing service to improve the status quo of the development of Wuhan manufacturing puts forward several policy suggestions: to set up the theme of Wuhan multidimensional collaborative innovation strategy as soon as possible, actively cultivate the introduction of a Service Manufacturing team of professionals, the development of service industry, improve the efficiency of resource allocation, and attaches great importance to the service and manufacturing business process design and optimization.

The problems need to be further studied: According to the manufacturing and service industries in Wuhan database and field survey data, the use of mathematical model hypothesis test research, inspection and the credibility of the conclusion is put forward.

\section{References}

[1] Li Gang origin, Conception and Value Creation of Service-Embeded manufacturing Science and Technology Progress and Policy. 2009,(7).

[2] Tian Xi. Research on the Influences that Productive Service Have to the Improvement of Competitiveness of China's manufacturing [D]. Master Thesis, Hunan University.

[3] Lin Lei, Wu Guisheng. The Enhancement Study of Manufacturing Services: Origin, Present Situation and Development [J]. Scientific Research Management, 2006, (1):91-99.

[4] Lin Lei, Wu Guisheng. Service Extension Product Differentiation: Service Enhancement Mechanisms is Discussed, based on the Hotel Location Model within the Framework of the Theory Analysis.[J] The Number of Economic and Technical Economic Research; 2005, (8):137-147 .

[5] Berger S, Lester 12.Made by Hong Kong [M]. Oxford: Oxford University Press, 1997.[6] Carson I ,The world as a single Machine [J]. The economist, 1998, 11(2):12-23.

[6] Gong Qinhui. A Service Manufacturing Research Were Reviewed. The Newspaper of Luzhou Vocational and Technical College. 2012,3.

[7] Sun Linyan, Gao Jie, Zhu Chunyan and so on. Service Manufacturing: Now Product Model and Manufacturing Paradigm.[J]. The Chinese Mechanical Engineering 2008,19 (21):2600-2608. 
[8] CARSON.The world as a Single Machine J/OL . The Economist (18 June 1998). A Manufacturing Survey. Available at: http://www.economist.com/surveys/ PrinterFriendly.cfm? Story_ID=168615.

[9] BERGER SLESTER R. Made by Hong Kong M. Oxford University Press 1997. 